\title{
COMPARATIVE OBSERVATIONS OF THE CHANGES IN CLASSES IN A THINNED AND NATURAL STAND OF IMMATURE DOUGLAS FIR
}

BY GEORGE WARRACK ${ }^{2}$

\author{
INTRODUCTION
}

In even-aged, fully stocked, and naturally regenerated stands of Douglas fir (Pseudotsuga taxifolia (Brit.)), the canopy differentiates into several storeys before 20 years. When a series of thinning plots was established in a 20-year-old forest at the Cowichan Lake Experiment Station by Schenstrom (1931), he expressed dominance by grouping trees, on the basis of height, according to Schotte's system. Definitions of the terms used were:

Class I -Dominant trees not less than 5/6ths top height;

Class II -Co-dominant trees between $2 / 3 \mathrm{rds}$ and $5 / 6$ ths top height;

Class III -Intermediate trees between $1 / 2$ and $2 / 3 \mathrm{rds}$ top height;

Class IV - Suppressed trees less than $1 / 2$ top height.

Repeated at ensuing examinations, this system of dominance classification now serves as a basis for a study and comparison of the behaviour of trees within canopy classes over a 20-year period.

\section{EXPERIMENTAL}

The analysis is confined to three plots within the series. Plot 65 is a control (natural) area. Experimental plots 64 and 66, initiated as crown- and low-thinnings, are presently samples of two stands thinned lightly at intervals of 10,7 , and 3 years respectively since a first thinning at 19 years of age. Within each plot a "descriptive part" - approximately $1 / 10$ th of an acre in size-was laid out at the start of the experiment, and because all trees within this smaller area have been identified in detail for individual description, they have been used to derive the results summarized for two 10-year periods in Tables 1 and 2 .

\section{Reduction Of Growing Stock}

Three factors contribute to this reduction: (a) movement of dominance classes, (b) mortality caused by natural competition and snowpress, (c) thinning procedures. At the time of their occurrence, factors (b) and (c) cause permanent loss to the standing-stock while (a) is associated with a loss of living trees from one class to another either up or down the dominance scale.

At the end of the 20-year period only 25,9, and 14 per cent of the original number of trees are present in C.P. 65 (control plot) E.P. 64 (crown-thinned) and E.P. 66 (low-thinned) respectively. It is quite evident there has been a big reduction in the growing stock and that when the net losses are allotted to dominance classes (Table 3 ), each class in all plots has lost the major proportion of its original trees with the exception of crownclass $I$ in C.P. 65 .

1 British Columbia Forest Service Publication T 37 . 2 British Columbia Forest Service. 


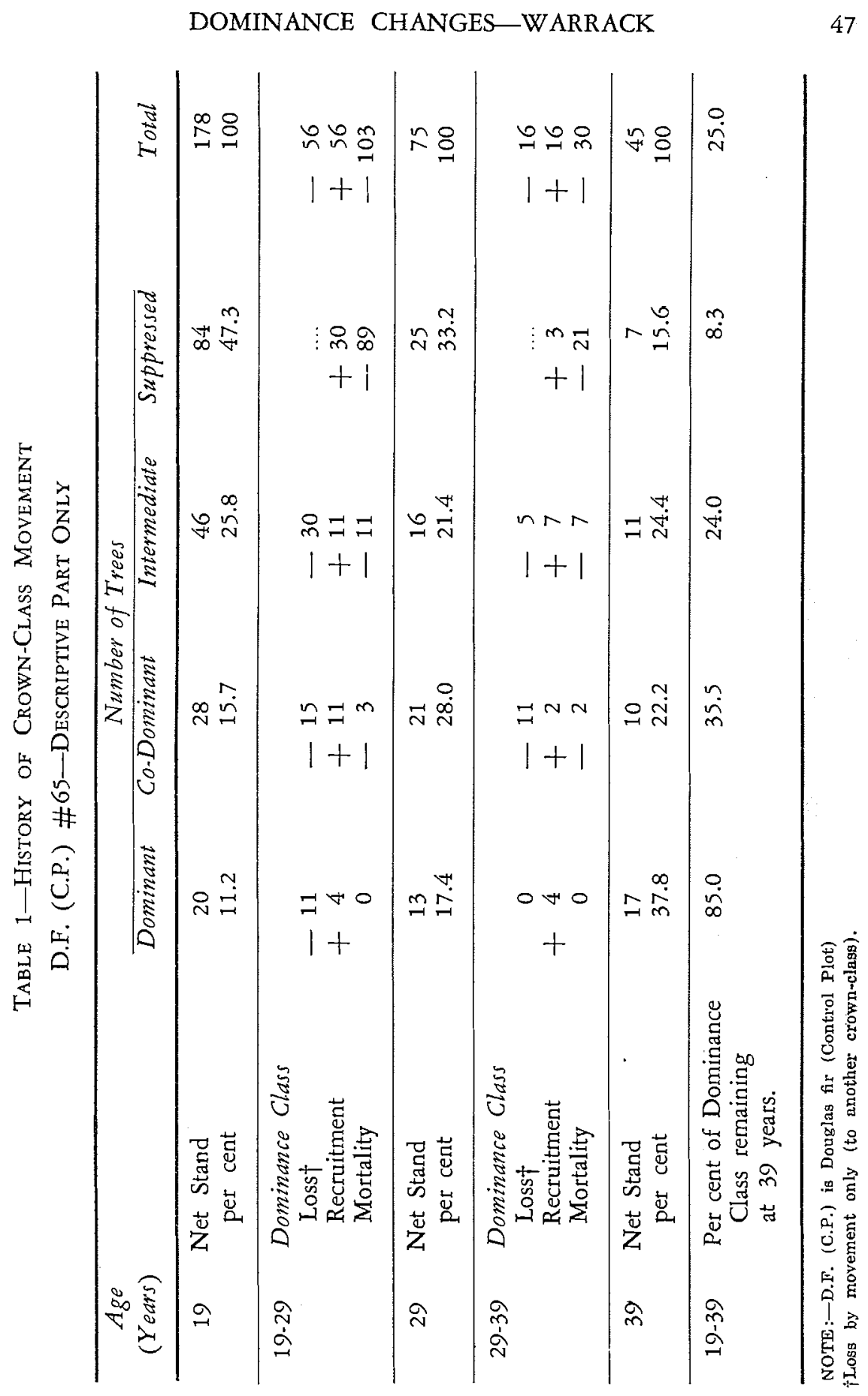


Table 3-Net Percentage loss by Dominance Classes FROM 19 TO 39 YEARS

\begin{tabular}{cccc}
\hline & \multicolumn{3}{c}{ Dominance Class } \\
\cline { 2 - 4 } PLOT & I & II & III \& IV \\
\hline 65 & 15.0 & 64.5 & 86.0 \\
64 & 71.5 & 82.7 & 96.3 \\
66 & 76.0 & 69.0 & 97.8 \\
\hline
\end{tabular}

In this plot, markedly lower loss is natural. The thinning agent is mutual competition causing losses among the individual components of the stand, which are seldom at the expense of dominant trees. In fact, the 15 per cent loss in Class I of C.P. 65 was entirely due to several dominant trees changing status and becoming Class II trees. This leads to consideration of movement between crown-classes.

\section{Movement of Trees among Dominance Classes}

From the loss and recruitment rows of Table I and Table II, it can be deduced that, during the first 10 year period, 31 per cent and 23 per cent of the growing stock in Plots 65 and 64 changed their dominance status. The change was related to a consistent movement downward through the classes. The trend was maintained in the second 10-year interval, between 29 and 39 years. Fewer trees actually changed their class, and the percentage they constituted of the growing stock at 29 years was reversed (21 per cent and 33 per cent) to that at the beginning of the first period. The characteristic downward movement was also exhibited by E.P. 66 in the two periods, but the amount of growing stock taking part in the shuffle varied considerably, being as high as 54 per cent between 19 and 29 years and only 18 per cent in the following 10 year period.

The individual class behaviour of trees in E.P. 64 may be cited and illustrated (Fig. 1) in detail as exemplifying the typical movement of classes in all plots. Fifty-four trees changed status in the canopy between the ages of 19 and 29 years. All of these 54 trees, with the exception of one codominant, moved in a downward direction. Of 14 Class I trees, 9 became Class II, and 5 dropped into the intermediate class due to snow breakage. All but two trees moving down from Class II entered Class III which in turn lost 25 trees to Class IV where they eventually died or fell to the axe. In the second interval, from 29 to 39 years, 3 trees moved up, 22 moved down. Three dominants became co-dominants and of 10 co-dominants, one was a recruit to Class I and 8 were relegated to Class III. One co-dominant, due to snow-damage, slid to Class IV where it was joined by 10 Class III trees, and all eleven trees were cut out in a thinning. Two Class III trees were re-classified as co-dominants; in no instance did intermediates ever become dominants. 
FORESTRY CHRONICLE

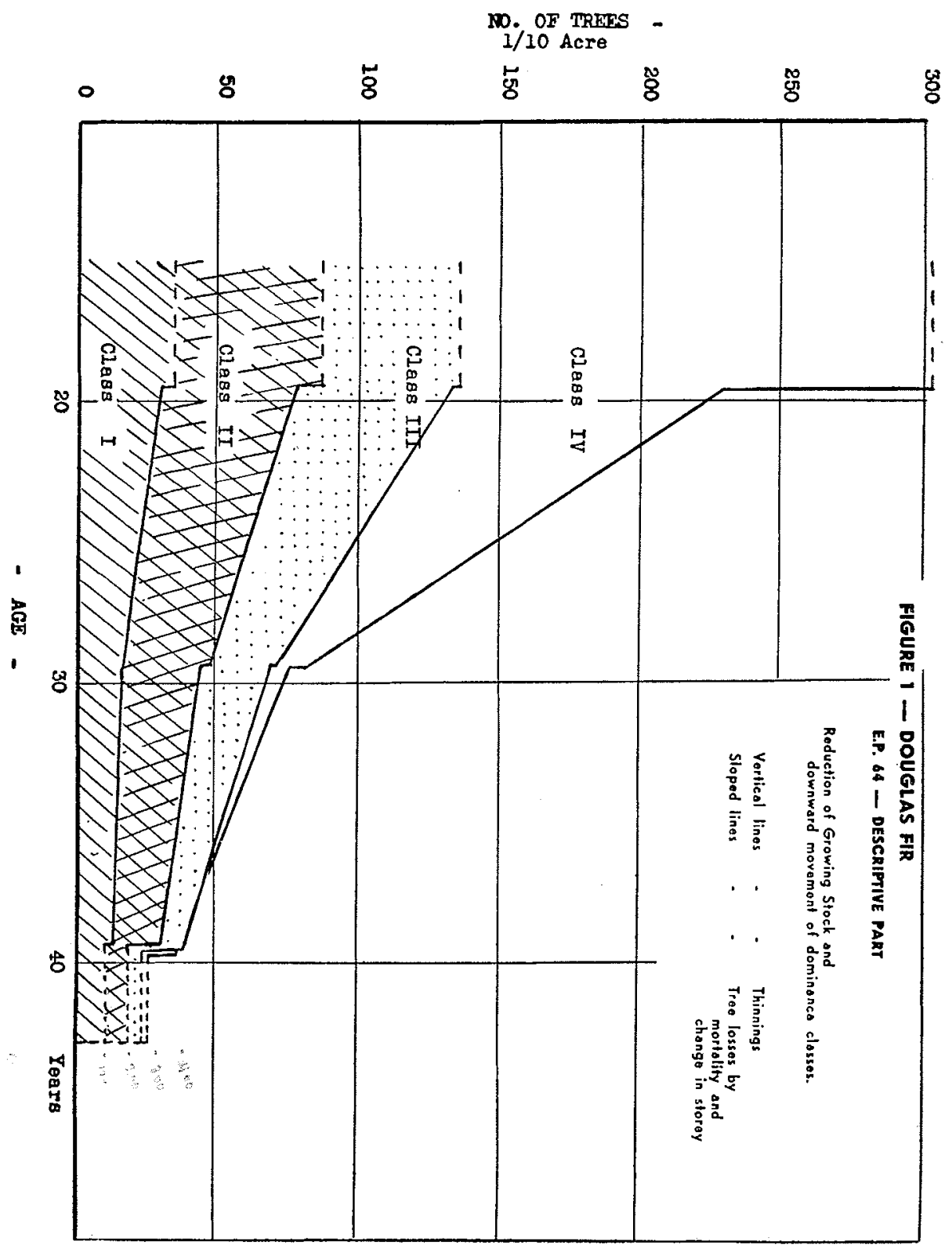


With the reduction of growing stock, therefore, there is a definite downward trend in the movement of tree-classes. A few trees exhibit a contrary movement and sound a minor note of significance in that, given adequate and early release, a small number of co-dominants can be expected to take the place of misshapen dominants.

This downward movement among Douglas fir tree-classes has been established in the findings of previous investigators, among the most recent of whom are Guillebaud and Hummel (1949). A comparison between the initial and final stocking and the distribution of the canopy classes in the Cowichan Lake plots and a B grade thinning plot (s. 38) for Douglas fir in Great Britain is made in Table 4.

Table 4 - Number and Percentage of Trees in Each Dominance Class at Beginning and End of Period

\begin{tabular}{|c|c|c|c|c|c|c|c|}
\hline \multirow[b]{2}{*}{ Species } & \multirow[b]{2}{*}{$\begin{array}{l}\text { Plot } \\
\text { No. }\end{array}$} & \multirow[b]{2}{*}{ Age } & \multicolumn{4}{|c|}{$\begin{array}{c}\text { Number (and in brackets } \% \text { ) of trees } \\
\text { per acre }\end{array}$} & \multirow{2}{*}{$\begin{array}{c}\text { Thinning } \\
\text { Grade }\end{array}$} \\
\hline & & & Dominants & $\begin{array}{l}\text { Co-domi- } \\
\text { nants }\end{array}$ & $\begin{array}{l}\text { Other } \\
\text { Classes }\end{array}$ & $\begin{array}{l}\text { Total } \\
100 \%\end{array}$ & \\
\hline \multirow{8}{*}{$\begin{array}{l}\text { Douglas fir } \\
\text { (Pseudotsuga } \\
\text { taxifolia } \\
(\text { Brit.) })\end{array}$} & & 19 & $335(9)$ & $485(14)$ & $2750(77)$ & 3570 & \\
\hline & 65 & 39 & $285(38)$ & $165(22)$ & $300(40)$ & 750 & None \\
\hline & & 19 & $405(12)$ & $595(18)$ & $2345(70)$ & 3345 & \\
\hline & 64 & 39 & $112(37)$ & $101(33)$ & $91(30)$ & 304 & Light High \\
\hline & & 19 & $720(30)$ & $430(18)$ & $1220(52)$ & 2370 & \\
\hline & 66 & 39 & $173(52)$ & $134(40)$ & $27(8)$ & 334 & Light Low \\
\hline & 38 & 15 & & $1130(40)$ & $1680(60)$ & 2810 & British "B" \\
\hline & & 38 & $299(68)$ & $104(24)$ & $36(8)$ & 439 & (light low) \\
\hline
\end{tabular}

A big reduction in growing stock and an increase in the proportion of Class I and Class II trees at the end of the period is common to all plots. E.P. 66 and S. 38, also a light low-thinned plot, agree closely in the distribution of canopy-classes both at the start and end of the period. At 39 and 38 years of age respectively, 92 per cent of the growing stock consists of dominant and co-dominant trees with a total of 8 per cent in all of the other classes. A higher proportion of dominants in S. 38 appears to be the result of a better thinning procedure than was practiced in E.P. 66. At 39 years the distribution of the classes in E.P. 64 provides a contrast in that only 70 per cent of the stand constitutes Class I and Class II trees. This was due to the nature of the last thinning which removed upper crown-classes to produce trees of an economic cutting diameter and left intermediate classes to minimize the effect of large gaps in the canopy. Actually, as a result of the thinning, the distribution of the canopy classes is similar to that of an unthinned stand (E.P. 65) at the same age, although of course the total number of trees have been reduced to increase the growing space of the best dominants.

In the control plot (E.P. 65) the net loss to Class I was only 3 trees. 
Although at the end of the first 10-year period over 50 per cent of the dominants moved downwards to class II, the loss was almost entirely balanced by recruitment from the co-dominants in the first and second periods.

A heavy loss in dominants in the first period followed by a few losses and a modest recruitment at older ages from the co-dominant class is an apparent development of the crown-storeys in each of the plots. An arrested downward movement of Class I trees after an age of 29 years contrasts with the continuing downward movement maintained by Classes II and below. This indicates, as might be expected, the superior stability of dominants in the community. A further measure of their importance is shown by the data for E.P. 65 which is free of any favouring influence that applied thinning techniques have on Class I trees. The proportion of dominants to the (net) number of trees in the stand had risen from 11.2 per cent at 19 years to 37.8 per cent at 39 years. Thus, with increasing age, an ever larger percentage of the growing stock will consist of the original dominants in the stand. Yet more striking evidence of the significance of the Class I trees is the distribution of volume increment among the tree-classes at 39 years. At this age in the natural stand dominant trees alone constitute 57 per cent of the total standing cubic volume (i.b.).

The investigation permits three general statements concerning the development of the stands in these Douglas fir sample plots between the ages of 19 and 39 years.

1. There has been a big reduction in the number of trees. The speed of this reduction was faster in the first than in the second ten-year period and in the lower than in the upper crown classes in either 10-year period.

2. Associated with this reduction of the growing stock there has been a gradual movement of a number of trees into lower crown storeys.

3. With increasing age of the stand, the ratio of Class I trees to all classes of trees becomes greater, so that at an age of 39 years in the natural stand, dominants contribute nearly 60 per cent of the total standing cubic volume (i.b.).

\section{DisCUSSION}

These results form a background to consideration of the thinning policy and practice adopted in these plots.

The policy has been to reduce the stand volume at age 20 years by 15 to 20 per cent at a first thinning. Stem-wise, this thinning was made up of trees, eighty per cent of which were Class II and III trees. Then, in the next two decades, a light grade thinning was employed at lengthy intervals, because, at no time under the then existing standards of utilization, were any trees of profitable cutting size.

- From a dominance-class viewpoint what lessons may be learned regarding the grade of thinning employed?

At the end of period, with the stand aged 39 years, there are considerably fewer trees. The majority of these trees are the original dominants from when the stand was 19 years old. This fact points to the importance of encouraging the Class I trees up to the limit of acceptable standards in number 


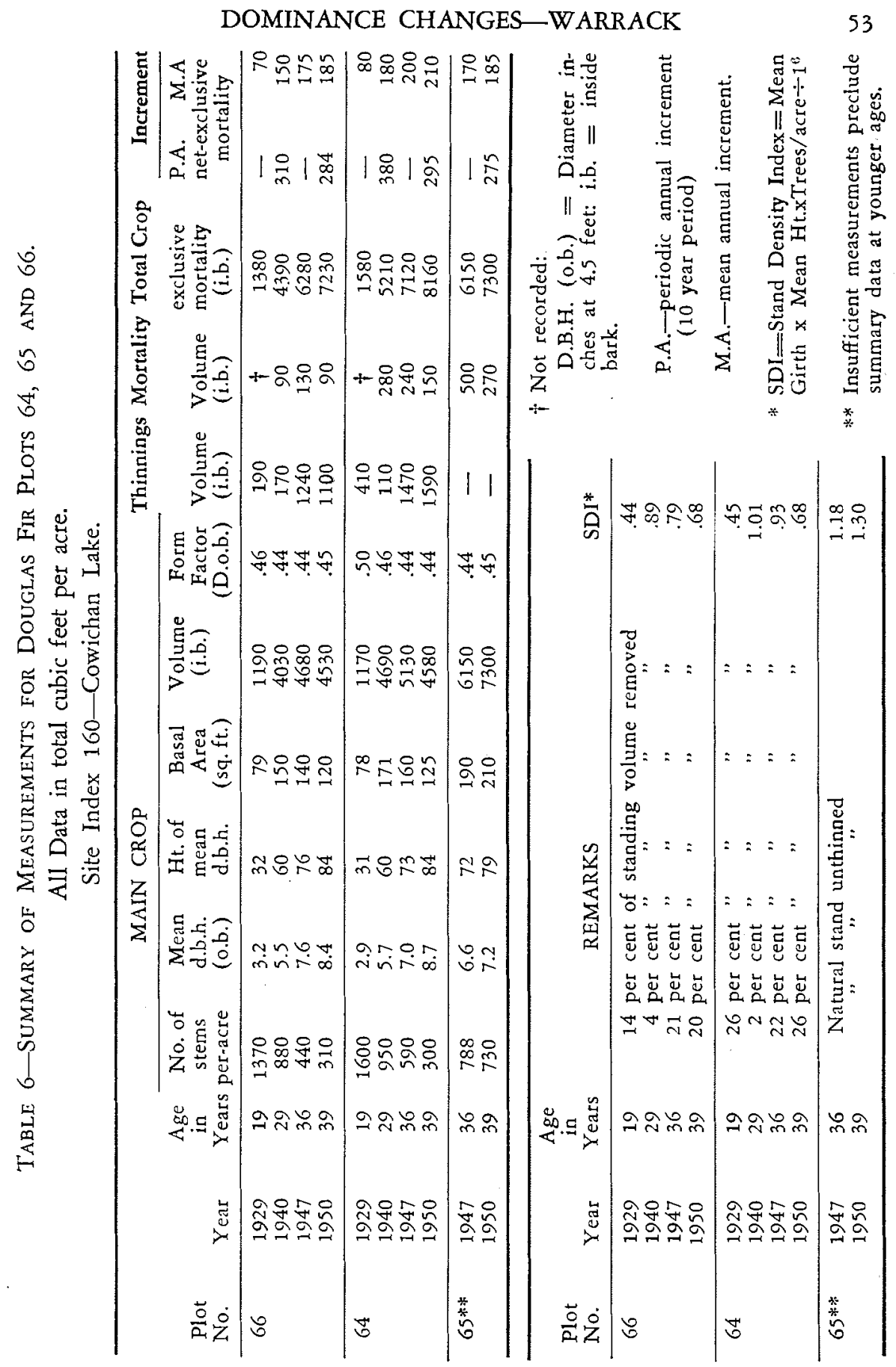


of rings per inch. No definite standard has yet been set, but such evidence as there is on the point indicates that 10 rings to the inch would be desirable.

Table 5 - Periodic Diameter (B.h.) InCREment (INCHes) by

Dominance Classes

(10 largest trees per plot)

\begin{tabular}{cccccccc}
\hline Dominance & \multicolumn{2}{c}{$1930-1940$} & & & \multicolumn{2}{c}{$1940-1950$} \\
\cline { 2 - 4 } \cline { 6 - 8 } Class & E.P. 65 & E.P. 64 & E.P. 66 & & E.P. 65 & E.P. 64 & E.P. 66 \\
\cline { 7 - 8 } \cline { 6 - 8 } I & 2.5 & 2.9 & 2.6 & & 1.7 & 2.2 & 1.8 \\
II & 2.3 & 2.0 & 2.0 & & 1.1 & 1.2 & 1.1 \\
III & 1.4 & 1.1 & 1.9 & & 0.4 & 0.7 & $1.0 \dagger$ \\
\hline
\end{tabular}
† Only 3 trees available to trace back 20 -year increment in E.P. 66 due to loss of trees by
thinning.

Thinning is a tool by which the percentage of dominants is increased at more rapid rate than can be accomplished by a process of mutual competition and elimination among the individual components in an even-aged stand. However, a degree of thinning which builds up the proportion of dominants at a pace sufficient only to forestall mortality in lower dominance classes can hardly be deemed satisfactory. In this category must be placed the thinning grade employed in E.P. 64 and E.P. 66 (See Summary Table 6 of plot measurements and Figure 2). Spasmodic and overly-light cutting has failed to produce appreciable increases in the diameter increment (b.h.) (Table 5) of dominant trees in the thinned plots when compared to those in the control plot. Moreover, because of the high number of Class II and Class III trees persisting over two decades, the diameter of the average tree for the entire plot is barely of economic conversion size at 7 to 8 inches (b.h.o.b.) at 36 years of age on a good site $(160)$.

Meanwhile at each operation the effort and time in selection, marking, and disposing of non-profitable trees has been apparently wasted in an abortive attempt to increase measurably the volume difference of dominants in a tended as against a natural plot.

Summarily, in comparison to the control plot, little has been achieved in treated plots towards producing larger trees or towards providing intermediate yields of merchantable quantities at earlier ages, in spite of considerable investments in thinning carried for 20 years.

\section{CONCLUSION}

Two alternatives present thenselves:

1. Practice no thinnings until there are a sufficient number of trees to warrant a profitable operation without removing all the large-diameter trees.

2. Anticipate the natural reduction in the growing stock by reducing density in a heavy, early cleaning so as to leave only the dominants and perhaps a few of the best co-dominants before the stand is 20 years old.

The standard set by alternative one, militates that thinnings may not commence before stands are 35 years of age or more. Since the majority of such stands are of fortuituous establishment, no hardship is involved other 
than the loss in volume increment ${ }^{2}$ represented by those trees which pass out of the stand due to the natural downward movement of tree-classes.

On the other hand, alternative two avoids waste of increment on a great number of trees which, if left to grow, afford undesirable competition to dominants and deter the tree of average diameter from reaching an economic size much before mid-rotation (let us say 40 years). One good cleaning at a moderate cost can ensure the production of material allowing a profitable cut at a first thinning long before 40 years, and because this thinning will be early two benefits should accrue.

Figure 2 - Comparison of Total Cubic Volume Production E.Ps. 65, 64, 66 - SITE INDEX 160.

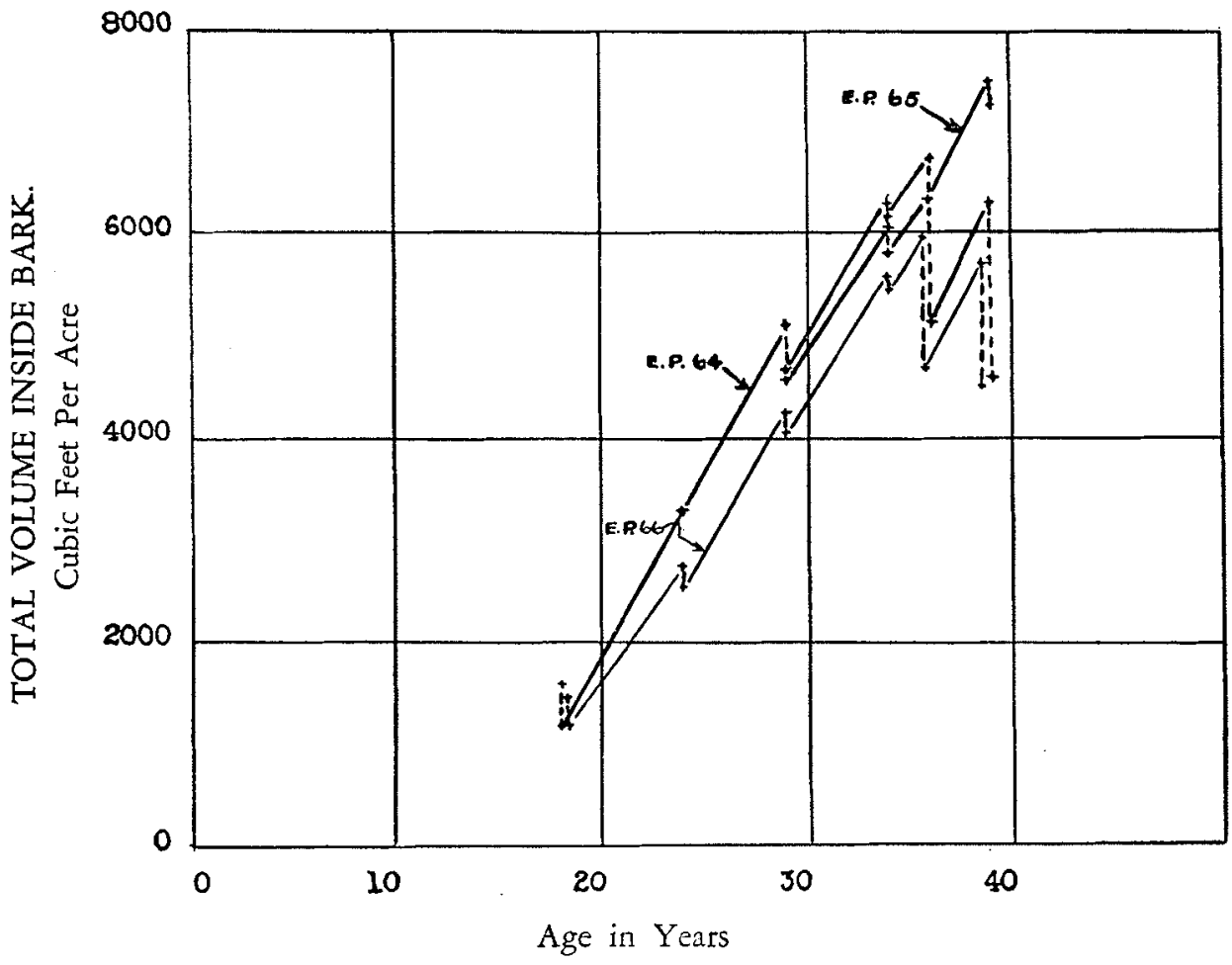

Points indicate time of examination or thinning.

Volume losses due to mortality plus thinning shown by vertical dotted lines.

Note over 78 per cent growth recovery of thinned volume in $P$. 64 and $P$. 66 between

36 and 39 years. 
(a) quick financial return on cleaning investment

(b) further reduction in density at a time when a high rate of increment can still be maintained on main crop trees.

Because the second alternative is still in a conjectural phase, yet to be supported by additional experiments on thinning cum-pruning techniques, the first suggestion remains the safe and likely choice for the immediate treatment of existing immature Douglas fir stands.

2 In the sixteen year period before the stand had reached the age of 36 years, over 11 per cent of the total volume per acre (inclusive of dead trees) had not been recovered in the unthinned plot.

1. GUILLEBAUD W. H. and HUMMEL

2. SCHENSTROM S. R. (1931)

0)

1. NYYSSONEN, AARNE (1950)

\section{Literature Cited}

A Note on the Movement of Tree Classes. Forestry, Vol. 23, pgs. 1-14.

Thinning Experiments in Douglas Fir Foresta of Britishr Columbia. Unpublished
Mss., B.C. Forest Service.
Comparative observations on the structure and
development of tended and natural pine development of tended and natural pine
stands. Silva Fennica 68 . Helsinki 